\title{
Patterns of Methamphetamine Use During Pregnancy: Results from the Infant Development, Environment, and Lifestyle (IDEAL) Study
}

\author{
Sheri Della Grotta $\cdot$ Linda L. LaGasse $\cdot$ Amelia M. Arria • \\ Chris Derauf · Penny Grant · Lynne M. Smith · Rizwan Shah • \\ Marilyn Huestis · Jing Liu • Barry M. Lester
}

Published online: 30 June 2009

(c) The Author(s) 2009. This article is published with open access at Springerlink.com

\begin{abstract}
The objectives of this study are to characterize methamphetamine (MA) usage patterns during pregnancy, examine whether patterns of MA use are associated with sociodemographic characteristics and prenatal care, and test the hypothesis that persistent or increasing MA use during pregnancy is associated with greater use of other illicit drugs. The sample consisted of 191 MA-using mothers who participated in a large-scale multi-site study
\end{abstract}

S. Della Grotta $(\bowtie)$ L. L. LaGasse · J. Liu · B. M. Lester Pediatrics Division, Brown Center for the Study of Children at Risk, Warren Alpert Medical School at Brown University and Women and Infant's Hospital, 101 Dudley Street, Providence 02905, RI, USA

e-mail: sdellagrotta@wihri.org

A. M. Arria

Center for Substance Abuse Research,

University of Maryland, College Park, MD, USA

C. Derauf

John A. Burns School of Medicine, University of Hawaii,

Honolulu, HI, USA

P. Grant

University of Oklahoma College of Medicine,

Oklahoma City, OK, USA

L. M. Smith

Los Angeles Biomedical Institute at Harbor-David Geffen

School of Medicine at UCLA, Los Angeles, CA, USA

R. Shah

Blank Children's Hospital-Iowa Health System,

Des Moines, IA, USA

M. Huestis

Chemistry and Drug Metabolism, Intramural Research Program,

National Institute on Drug Abuse, Baltimore, MD, USA of prenatal MA exposure. Patterns of substance use were assessed by maternal self-report via the Substance Use Inventory (SUI), which included detailed information about MA use, including frequency, quantity, and maximum use during each trimester of pregnancy. The study demostrated that on average, the prevalence of MA use decreased over the three trimesters of pregnancy (84.3\% vs. $56.0 \%$ vs. $42.4 \%$ ), and decreased frequency was observed among users from the first trimester to the third ( 3.1 vs. 2.4 vs. 1.5 days/week). Closer examination of the individual patterns revealed that $29.3 \%$ of women maintained consistently high frequency, $9.4 \%$ increased frequency, $25.7 \%$ had a stable low/moderate pattern, and $35.6 \%$ decreased their frequency of MA over the course of pregnancy. These four groups did not differ in sociodemographic characteristics; women who decreased their use of MA had significantly more prenatal visits compared to the consistently high-use group, but were the most likely to use alcohol during their pregnancy. In conclusion, this article elucidated the different patterns of MA use in this community sample. Approximately, one third of MA-using mothers could be classified as consistently high users with a profile of use with the greatest risk to themselves and potentially to their infants including high levels of MA use throughout pregnancy and fewer prenatal care visits. Overall, we found that MA use declined across pregnancy; however, a substantial proportion of users had consistently high or increasing MA use, while those who decreased their MA frequency had a higher prevalence of polydrug use. Future research will investigate the association of these patterns with neonatal outcomes.

Keywords Methamphetamine - Pregnancy . Alcohol and other drug use - Women · Epidemiology 


\section{Introduction}

Methamphetamine (MA) use in the U.S. and in other regions of the world remains a very serious public health concern [1-7]. The latest data from the National Survey on Drug Use and Health (NSDUH), an ongoing national probability survey, estimates that $5.8 \%$ of persons ages 12 and older (approximately 14.2 million people) used MA at least once in their lifetime, including prescription MA. This may have been underestimated in NSDUH due to its inclusion within a set of questions about prescription-type drugs. Specifically, survey respondents who used methamphetamine might not have reported its use when questions about it were asked in the context of other questions about prescription pharmaceuticals.

Other evidence for the magnitude of the MA problem comes from the Treatment Episode Dataset (TEDS), which monitors national trends in drug treatment. From these data, drug treatment admissions where the primary substance use problem was MA more than doubled between 1995 and 2005, from 3.7 to $9.2 \%$ [8, 9]. While Western regions of the U.S. have the highest prevalence of users, almost all states have experienced increases in treatment admissions [10], and non-urban areas are more affected than major metropolitan areas [5, 11]. The sites included in the present study (Iowa, California, Hawaii and Oklahoma) rank in the top ten with respect to the highest rates of MA treatment admissions [10].

Few studies have attempted to examine the prevalence of MA use during pregnancy [12]. Further, the epidemiology of the prevalence of methamphetamine use during pregnancy currently available is limited, varies widely and is not systematic. According to the 2006-2007 NSDUH, an ongoing national probability survey, MA use in pregnant women is reported as $0.1 \%$. The National Pregnancy and Health Survey (NPHS), based on self-reported use and urine toxicology, reports less than one percent during pregnancy. The 2005 TEDS data from client treatment admissions, estimates a prevalence of one percent. Due to the methodological limitations in these national surveys, the true estimated prevalence of MA use in pregnancy is likely to be underestimated, which could be attributed to underreporting and surveys not sampling high-risk women living in rural areas. Estimating the true prevalence of prenatal MA use can be rather complex because of issues around sampling methods, accurate self-reported drug use information and procedures used to detect prenatal drug use. The available epidemiologic studies on drug use during pregnancy are limited in that they report whether or not use occurred, rather than the amount used [13]. These estimates vary on the basis of the population sampled, methods used to collect drug use information and the time period of data collection [13].
In 2002, we began a study of MA-using mothers and a matched comparison group to better understand the impact of prenatal MA exposure and a variety of concomitant environmental factors on long-term child outcomes. We reported that $5.2 \%$ of pregnant women living in these areas highly affected by MA use MA during their pregnancy [14].

The present study follows up these initial findings by looking more closely at patterns of MA use during pregnancy. To our knowledge, no prior studies have systematically described MA use patterns among pregnant substance-using women. Findings from the NSDUH, including the prevalence of past 30-day alcohol and other drug use among 15-44 year old pregnant women by trimester, suggest that women reduce their use of illicit drugs from the first trimester to the last; however, specific information is not available on the changing patterns of MA use during pregnancy [6]. There are two important reasons why the pattern of MA use during pregnancy is useful to establish. First, from a scientific standpoint, it is important to establish a pattern of use in pregnant MA users because this information will be crucial to establishing a dose-response relationship between MA use and neonatal outcomes. Different patterns of MA use might very well be associated with different neonatal outcomes. Short-term neonatal outcome studies from our investigative team have observed small deficits in infant neurobehavioral functioning and growth restriction in MA-exposed infants compared to a matched comparison group $[15,16]$. These studies compared users with non-users but did not relate neonatal outcomes to quantity and frequency of MA use, nor consistency of MA use across trimesters. Developing a typology of MA use during pregnancy can refine the methodology used in future studies of prenatal MA exposure and infant outcomes.

Second, from a clinical standpoint, it is important to understand whether sociodemographic subgroups vary with regard to their MA use pattern. If so, interventions to reduce use during pregnancy could be tailored to have maximum impact. Moreover, it would be useful to understand if various MA use patterns during pregnancy are associated with different profiles of concomitant use of tobacco, alcohol and other drugs. Although some earlier studies have documented MA use during pregnancy and the association with polydrug use [17], little information is available about changing patterns of use during the course of pregnancy.

The purpose of this study was threefold: (1) to describe MA use patterns during pregnancy, in terms of quantity and frequency changes over the course of pregnancy; (2) to examine whether women with different patterns of MA use differed with respect to sociodemographic characteristics; and (3) to test the hypothesis that continued MA use over 
the course of pregnancy is indicative of a more severe drug problem, and thus associated with greater use of alcohol, tobacco and other illicit drugs.

\section{Methods}

\section{Overview}

The study is part of the Infant Development Environment and Lifestyle (IDEAL) Study, a multi-site, longitudinal study of prenatal MA exposure and infant and childhood outcomes. The IDEAL study involves four clinical sites in specific geographic areas of the U.S. known to have MA problems-Los Angeles, CA; Des Moines, IA; Tulsa, OK; and Honolulu, HI. At each of the sites, as described below, MA-using women and their infants were recruited at the time of delivery and enrolled in this longitudinal study. Training and re-training of staff occurred at regular intervals to maintain standardization in data collection activities. The study protocol and consent forms were approved and reviewed by the Institutional Review Board at each site and a Certificate of Confidentiality was obtained from the National Institute on Drug Abuse to assure the confidentiality of information and truthfulness in reporting the woman's prenatal drug use. Women were also informed that should there be any evidence of abuse or neglect, staff at each site would be mandated to report it. Briefly, at each of the four clinical sites, all women delivering were approached for consent to participate in IDEAL. The major reasons for ineligibility include being non-English speaking, non-singleton births, and cognitive deficits in the mother that would preclude informed consent. MA-using mothers and her matched comparison were identified by self-report and/or meconium sample results. An earlier publication details the original methods used to screen for eligibility and recruit mothers into the IDEAL study [14]. Subjects who reported use of any opiate, LSD and PCP were excluded from the study. Among all eligible women approached for the study, $23 \%$ provided informed consent.

\section{Study Participants}

There were 204 women classified as MA exposed. Eight (1.9\%) subjects who denied the use of MA were identified as exposed by toxicology only; these women were not included in this study because the pattern of use could not be determined; 196 (47.5\%) subjects disclosed any amphetamine use, including ecstasy and other amphetamines. Since the reported unit for ecstasy and other amphetamines could not be converted to a gram equivalent $(N=5)$, we excluded them in this study. Two subjects reported amphetamine and MA and two subjects reported ecstasy and MA. In these cases only MA use is described. To examine polydrug use, we also measured prenatal use of maternal alcohol, marijuana, and tobacco use in selfreported MA users $(N=191)$ (See Fig. 1).

\section{Measures}

Each participant was administered the Recruitment Lifestyle Interview [18, 19], which covered the following
Fig. 1 MA exposed subjects in the current study $(N=191)$

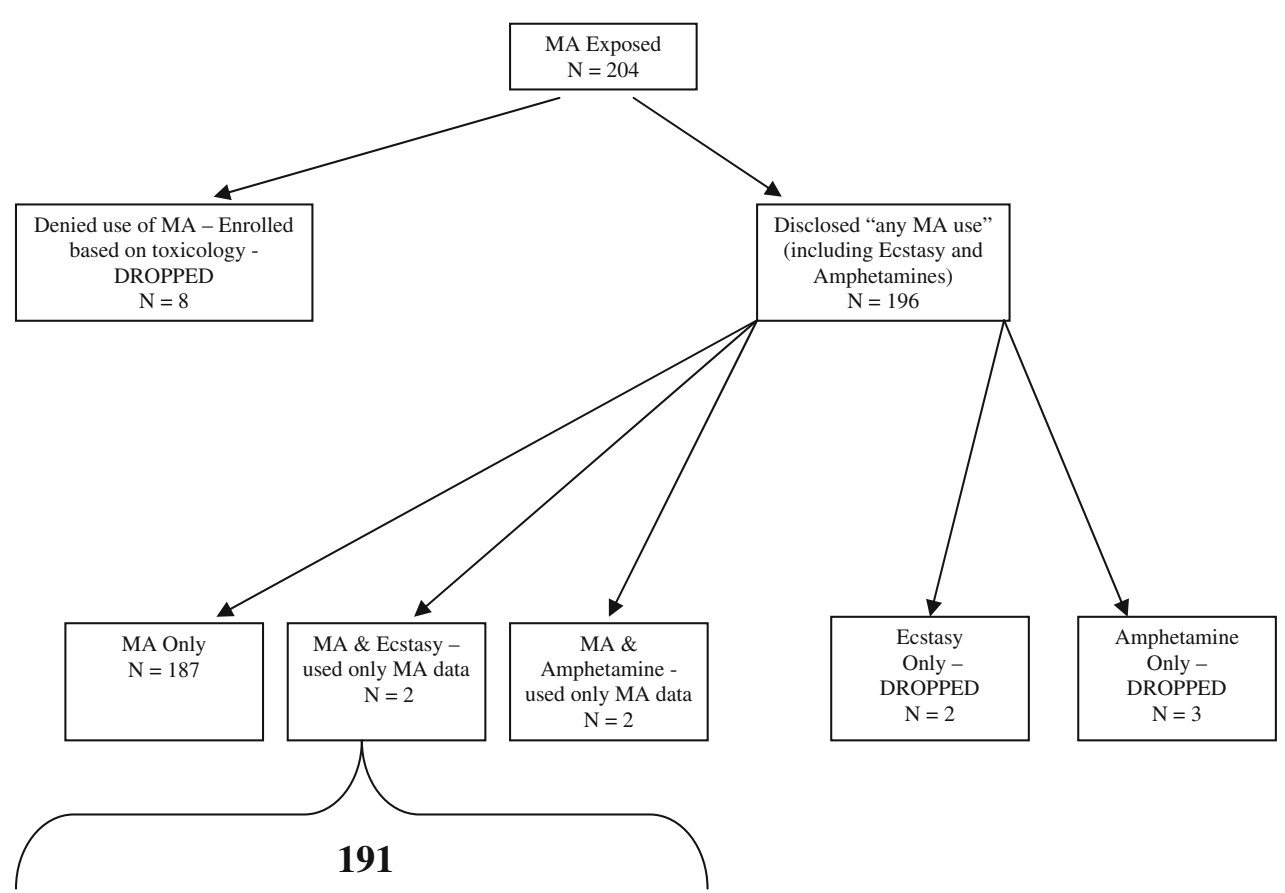


topics: (1) information about the course of her pregnancy and number of prenatal care visits; (2) demographics, including education, age, race, marital status, type of insurance, and socioeconomic status (SES), calculated using the four-factor Hollingshead index with group 5 indicating low SES [20]; (3) licit and illicit drug use during pregnancy, assessed by asking "During your pregnancy, have you used any of the following drugs?" followed by a series of 14 classes of substances (i.e., methamphetamine, ecstasy, amphetamines, cocaine, tobacco, alcohol, marijuana, hashish, benzodiazepines/tranquilizers, barbiturates/ sedatives, heroin/methadone, other opiates, LSD, and PCP). Exposure status for all illicit drugs, alcohol, and tobacco was determined by maternal self-report and meconium toxicology (relevant for use during the later stages of pregnancy), except for alcohol which was based solely on self-report.

For each drug used during pregnancy, a separate series of questions was asked using the Substance Use Inventory (SUI), an interview that elicits retrospective reports of frequency and quantity of drug and alcohol use during four time periods: 3 months prior to pregnancy and during the first, second, and third trimester of pregnancy. This questionnaire is based on the Maternal Inventory of Substance Use (MISU) used in the Maternal Lifestyle Study [21] and others [22-25]. To assist in recall for each drug used, the interviewer introduced a calendar with trimesters outlined, as well as important dates specific to the postpartum woman, such as birthdays, anniversaries, holidays, and any other significant life event she was willing to share.

For MA use, the SUI captures age of first use; typical quantity used per day on days of use; average number of days in 1 week that the average amount was used (every day, almost every day, 3-4 times week, 1-2 times week, 2-3 times month, once/month, 1-2 times/trimester); cost; maximum used in 1 day (grams, pills, plates, bowls, other); and route of administration (sniff/snort, ingest, smoke, inject). For questions pertaining to quantity, participants were prompted to report use in grams. If the quantity in grams was unknown, then "props" were used (e.g., a sugar packet, in which the contents were equal to $1 \mathrm{~g}$ ) to help the participant estimate the number of grams. Five subjects were unable to report the quantity of MA used during pregnancy. On some occasions, participants used a variety of street names to report the specific quantity of MA used, and these were converted to grams based on standard and fairly well-known definitions (i.e., an "eight ball" is equivalent to $3.5 \mathrm{~g}$ or a "teener" (teena or teenager) is equivalent to $1 / 16$ of an ounce which equals $1.75 \mathrm{~g}$ ). However, less familiar terms, such as "quarter paper," "a line," "bumps," and "\$20 paper" were converted to gram quantities using information from drug enforcement agencies, drug treatment facilities, and local key informants.
Conversion estimates were acceptable if they could be verified with two sources of data.

A variable was constructed for frequency of MA use based on the number of days per week that the average quantity was used. Estimates for "average use" were generated for each trimester separately. Interviewers were trained to factor in periods of quitting or "no use" into the estimate of average frequency during the trimester.

\section{Data Reduction}

Several summary indices to reflect MA use by trimester were computed, using means and medians including frequency of MA used per week, quantity of MA per occasion of use, grams/week (quantity multiplied by frequency) and maximum quantity of MA use. Further, quantity and frequency of tobacco, alcohol and marijuana use were summarized as the number of cigarettes per day, absolute alcohol per day (ounces), and number of joints per day (marijuana).

\section{Defining Methamphetamine Use Patterns During Pregnancy}

Because no "standard" definition exists for MA use patterns during pregnancy, we developed a typology of changing use patterns during the course of pregnancy using frequency of use based on studies of prenatal cocaine use [21, 26-29]. First, the frequency of MA use during each trimester was categorized as high, moderate, low/no use. High use was defined as more than 1 day per week, moderate use was defined as one to 3 days per month, and low use was defined as no use or less than or equal to 1-2 days in 3 months. The pregnancy was divided into "the early period" (the first trimester) and "the late period", which spanned the second and third trimesters. The late period was assigned the highest frequency of either the 2nd or 3rd trimester. Stability and change of MA use was determined by comparing the frequency between the early period and the late period and described as consistently high if there was high use in both the early and late periods, increasing use if there was increasing use from the early to the late period, stable low/moderate if there was low or moderate use in the early and late periods, decreasing use if there was a decrease from the early period to the late period.

\section{Statistical Analysis}

Version 12.0.1 of SPSS $^{\circledR}$ for Windows ${ }^{\circledR}$ (Chicago, IL) was used for all data analyses. Descriptive statistics (means and medians) show the quantity and frequency of MA use during pregnancy in Table 1. The Cochran-Armitage Trend Test (one sided) was used to test decreasing MA use across 
Table 1 Frequency and quantity of methamphetamine (MA) use during pregnancy, by trimester $(N=191)$

\begin{tabular}{|c|c|c|c|c|c|c|}
\hline \multirow[t]{2}{*}{ Frequency of MA Use } & \multicolumn{2}{|c|}{ First trimester } & \multicolumn{2}{|c|}{ Second trimester } & \multicolumn{2}{|c|}{ Third trimester } \\
\hline & $n$ & $\%$ & $n$ & $\%$ & $n$ & $\%$ \\
\hline No use & 30 & 15.7 & 84 & 44.0 & 110 & 57.6 \\
\hline Some use & 161 & 84.3 & 107 & 56.0 & 81 & 42.4 \\
\hline 1-2 times/pregnancy & 28 & 14.7 & 23 & 12.0 & 34 & 17.8 \\
\hline Once/month & 4 & 2.1 & 8 & 4.2 & 8 & 4.2 \\
\hline $2-3$ times/month & 13 & 6.8 & 13 & 6.8 & 7 & 3.7 \\
\hline 1-2 times/week & 29 & 15.2 & 20 & 10.5 & 13 & 6.8 \\
\hline 3-4 times/week & 42 & 22.0 & 22 & 11.5 & 9 & 4.7 \\
\hline Almost everyday/daily & 45 & 23.6 & 21 & 11.0 & 10 & 5.2 \\
\hline \multirow[t]{4}{*}{ Average days/week } & Mean & SD & Mean & SD & Mean & $\mathrm{SD}$ \\
\hline & 3.1 & 2.5 & 2.4 & 2.5 & 1.5 & 2.1 \\
\hline & Median & Range & Median & Range & Median & Range \\
\hline & 3.5 & $0.1-7$ & 1.5 & $0.1-7$ & 0.2 & $0.1-7$ \\
\hline Quantity of MA & Mean & SD & Mean & SD & Mean & $\mathrm{SD}$ \\
\hline Grams/use & 0.7 & 1.3 & 0.7 & 1.2 & 0.4 & 0.9 \\
\hline Grams/week & 3.0 & 6.3 & 1.9 & 5.3 & 1.4 & 6.0 \\
\hline \multirow[t]{2}{*}{ Maximum (g/use) } & 1.2 & 2.7 & 0.8 & 1.4 & 0.5 & 1.1 \\
\hline & Median & Range & Median & Range & Median & Range \\
\hline Grams/use & 0.29 & $0.02-10.5$ & 0.25 & $0.02-9.0$ & 0.25 & $0.02-7.0$ \\
\hline Grams/week & 0.88 & $0.004-49.0$ & 0.44 & $0.002-49.0$ & 0.06 & $0.002-49.0$ \\
\hline Maximum (g/use) & 0.5 & $0.02-28.4$ & 0.5 & $0.02-9.0$ & 0.25 & $0.02-7.0$ \\
\hline
\end{tabular}

pregnancy. One-way analysis of variance (ANOVA) with Tukey-HSD post hoc analyses were used to examine mean differences between use pattern groups and frequency and quantity measures (Table 2), prenatal and sociodemographic characteristics in Table 3 and other substance use in Table 4. Chi Square analysis was used to test categorical data in Tables 3 and 4. Results were considered significant at the 0.05 level. Medians were included for informational purposes only.

\section{Results}

Patterns of Methamphetamine Use Characteristics by Trimester

Table 1 shows the extent to which MA use declined during the course of pregnancy among the entire sample. Specifically, $84.3 \%$ of women used MA in the first trimester, which declined to $56.0 \%$ in the second trimester and $42.4 \%$ in the third trimester $(\mathrm{Z}=8.39, P<0.001)$. During the first trimester of pregnancy, almost a quarter of women used MA every day or almost everyday, which declined to 11.0 and $5.2 \%$ in the last two trimesters, respectively. While the mean number of days used per week and mean number of grams per week also declined among users, quantity of MA per use during each trimester was stable for the first two trimesters and then declined in the third trimester. Maximum quantity also showed a decrease from $1.2 \mathrm{~g}$ in the first, $0.8 \mathrm{~g}$ in the second to $0.5 \mathrm{~g}$ in the third.

Patterns of Methamphetamine Use During Pregnancy

There was substantial heterogeneity with respect to individual MA use patterns among women in the sample. As shown in Table 2, $29.3 \%$ of women were classified as consistently high users, a smaller proportion $(9.4 \%)$ increased their use (or started their use) in the second trimester or later, another quarter $(25.7 \%)$ had a stable low/ moderate level of use during all trimesters, and the remaining $35.6 \%$ decreased their use over the course of pregnancy.

Table 2 compared the use pattern groups to quantity by frequency measures. Women in the consistently high use group had significantly higher mean frequency of MA use per week than all of the other groups (all $P \mathrm{~s}<0.001$ ). Women who increased their MA use across the pregnancy had a significantly higher mean frequency of MA use compared to women who had a stable low/moderate frequency $(P<0.001)$. The women in the decreasing group used a significantly greater number of days per week compared to the stable low/moderate $(P<0.001)$. 
Table 2 Methamphetamine use patterns during pregnancy among 191 methamphetamine-using pregnant women

\begin{tabular}{|c|c|c|c|c|}
\hline & \multicolumn{4}{|c|}{ Methamphetamine use pattern during pregnancy } \\
\hline & $\begin{array}{l}\text { Consistently high }{ }^{\mathrm{a}}(n=56) \\
29.3 \%\end{array}$ & $\begin{array}{l}\text { Increasing }^{\mathrm{b}}(n=18) \\
9.4 \%\end{array}$ & $\begin{array}{l}\text { Stable low/moderate }{ }^{\mathrm{c}}(n=49) \\
25.7 \%\end{array}$ & $\begin{array}{l}\text { Decreasing }^{\mathrm{d}}(n=68) \\
35.6 \%\end{array}$ \\
\hline Mean frequency (days/week) & $4.0^{\mathrm{e}}$ & $1.92^{\mathrm{e}, \mathrm{f}}$ & $0.16^{\mathrm{e}, \mathrm{f}, \mathrm{g}}$ & $2.48^{\mathrm{e}, \mathrm{g}}$ \\
\hline SD & 1.85 & 1.99 & 0.15 & 1.70 \\
\hline Median frequency (days/week) & 3.5 & 0.9 & 0.1 & 1.8 \\
\hline Range & $(1.0-7.0)$ & $(0.2-7.0)$ & $(0.1-0.6)$ & $(0.15-7.0)$ \\
\hline Mean quantity (g/use) & 0.67 & 0.50 & 0.44 & 0.92 \\
\hline SD & 1.00 & 0.73 & 0.68 & 1.68 \\
\hline Median quantity (g/use) & 0.4 & 0.2 & 0.3 & 0.3 \\
\hline Range & $(0.08-7.0)$ & $(0.04-2.8)$ & $(0.03-3.5)$ & $(0.02-10.5)$ \\
\hline Mean (g/week) & $3.46^{\mathrm{h}}$ & 1.65 & $0.06^{\mathrm{h}, \mathrm{i}}$ & $2.87^{\mathrm{i}}$ \\
\hline SD & 7.00 & 3.49 & 0.07 & 6.11 \\
\hline Median (g/week) & 1.4 & 0.3 & 0.03 & 0.8 \\
\hline Range & $(0.1-49.0)$ & $(0.01-13.9)$ & $(0.003-0.4)$ & $(0.02-36.8)$ \\
\hline Mean maximum quantity (g) & 0.94 & 0.56 & 0.56 & 1.63 \\
\hline SD & 1.33 & 0.90 & 0.89 & 3.91 \\
\hline Median maximum quantity $(\mathrm{g})$ & 0.5 & 0.2 & 0.3 & 0.5 \\
\hline Range & $(0.09-7.0)$ & $(0.03-3.7)$ & $(0.03-4.0)$ & $(0.01-28.4)$ \\
\hline
\end{tabular}

${ }^{a}$ MA use $>1$ day per week (high) across pregnancy $(\mathrm{CH})$

${ }^{\mathrm{b}}$ Low-moderate, low to high, moderate to high patterns of MA use (I)

c MA use $\leq 1-2$ days in 3 months (low), 1-3 days per month (moderate) across pregnancy (SLM)

${ }^{\mathrm{d}}$ High to moderate, high to low, moderate to low patterns of MA use (D)

e $\mathrm{CH}>\mathrm{I}(P<0.001), \mathrm{SLM}(P<0.001), \mathrm{D}(P<0.001)$

${ }^{\mathrm{f}} \mathrm{I}>\operatorname{SLM}(P<0.001)$

g $\mathrm{SLM}<\mathrm{D}(P<0.001)$

${ }^{\text {h }} \mathrm{CH}>\operatorname{SLM}(P=0.010)$

${ }^{\mathrm{i}} \mathrm{SLM}<\mathrm{D}(P=0.010)$

Compared to woman in the stable low/moderate group, woman in both the consistently high use group $(P=0.010)$ and stable low/moderate group $(P=0.010)$ used more grams per week of MA. No other significant group differences were observed including typical quantity used or maximum quantity used.

\section{Sociodemographic Characteristics} and Methamphetamine Use Pattern

Table 3 compares the sociodemographic characteristics of the four MA use pattern groups. There were no significant differences in race/ethnicity, education, SES, insurance status, marital status, or maternal age. Further there were no significant differences of MA use pattern groups and site $\left(\chi^{2}=7.71\right.$, df $\left.=9, P=0.564\right)$.

Overall, $38.7 \%$ of the sample was White, about one quarter Hispanic, and a third were Pacific Islander/Asian. Minority representation mirrored the variations that existed in the local regions in which the study was conducted.
Thus, race was significantly different across sites $\left(\chi^{2}=111.18, \mathrm{df}=9, P<0.001\right)$. Whites were predominant in Iowa and Oklahoma $(N=16,89 \%, N=18,69 \%$, respectively), Pacific Islander/Asians in Hawaii $(N=51$, $70 \%)$, and Hispanics in California $(N=36,49 \%)$. There were no significant differences among sites in education, insurance status, and marital status. On the other hand, the percentage of low SES was higher in Hawaii $(N=31$, $42 \%)$ and California $(N=26,36 \%)$ relative to Iowa $(N=4,22 \%)$ and Oklahoma $(N=2,8 \%)$.

Overall and consistent with our previous report [14], almost half of the women who used MA during pregnancy had less than a high school education, a vast majority had either public or government funded health insurance, and over half reported not having a partner. The average age of the sample was 26 years old.

A statistically significant association was observed between the MA use pattern group and prenatal care visits $(P=0.004)$. Women who decreased their MA use over the course of pregnancy had significantly more prenatal care 
Table 3 Comparison of prenatal and sociodemographic characteristics by methamphetamine use pattern

\begin{tabular}{|c|c|c|c|c|c|c|c|c|c|c|}
\hline & \multicolumn{10}{|c|}{ Methamphetamine use pattern during pregnancy } \\
\hline & \multicolumn{2}{|c|}{$\begin{array}{l}\text { Consistently high } \\
(n=56)\end{array}$} & \multicolumn{2}{|c|}{$\begin{array}{l}\text { Increasing } \\
(n=18)\end{array}$} & \multicolumn{2}{|c|}{$\begin{array}{l}\text { Stable low/moderate } \\
(n=49)\end{array}$} & \multicolumn{2}{|c|}{$\begin{array}{l}\text { Decreasing } \\
(n=68)\end{array}$} & \multicolumn{2}{|c|}{$\begin{array}{l}\text { Total } \\
(n=191)\end{array}$} \\
\hline & $n$ & $\%$ & $n$ & $\%$ & $n$ & $\%$ & $n$ & $\%$ & $n$ & $\%$ \\
\hline \multicolumn{11}{|l|}{ Race } \\
\hline White, Non-Hispanic & 19 & 33.9 & 6 & 33.3 & 19 & 38.8 & 30 & 44.1 & 74 & 38.7 \\
\hline African-American/Black, Non-Hispanic & 2 & 3.6 & 0 & 0.0 & 1 & 2.0 & 5 & 7.4 & 8 & 4.2 \\
\hline Hispanic & 10 & 17.9 & 3 & 16.7 & 13 & 26.5 & 17 & 25.0 & 43 & 22.5 \\
\hline Pacific Islander/Asian & 25 & 44.6 & 9 & 50.0 & 16 & 32.7 & 16 & 23.5 & 66 & 34.6 \\
\hline Education $<12$ years & 29 & 51.8 & 7 & 38.9 & 25 & 51.0 & 26 & 38.2 & 87 & 45.5 \\
\hline Low SES & 24 & 42.9 & 6 & 33.3 & 15 & 30.6 & 18 & 26.9 & 63 & 33.2 \\
\hline Public/Govt insurance & 49 & 87.5 & 17 & 94.4 & 45 & 91.8 & 61 & 89.7 & 172 & 90.1 \\
\hline \multirow[t]{2}{*}{ Marital status (\% no partner) } & 33 & 58.9 & 10 & 55.6 & 26 & 53.1 & 40 & 58.8 & 109 & 57.1 \\
\hline & Mean & SD & Mean & SD & Mean & SD & Mean & SD & Mean & $\mathrm{SD}$ \\
\hline Age (years) & 26 & 5.7 & 26 & 5.6 & 27 & 6 & 26 & 5.5 & 26.0 & 5.7 \\
\hline Number of prenatal visits & $8^{\mathrm{a}}$ & 5.5 & 11 & 8 & 12 & 7.5 & $13^{\mathrm{a}}$ & 7.9 & 11.3 & 7.4 \\
\hline Gestational age at 1 st prenatal visit (week) & $17.8^{\mathrm{b}}$ & 7.3 & 14.3 & 9.9 & $12.5^{\mathrm{b}}$ & 8.1 & $13.3^{\mathrm{b}}$ & 7.2 & 14.5 & 8.0 \\
\hline
\end{tabular}

${ }^{\mathrm{a}} \mathrm{CH}<\mathrm{D}(P=0.004)$

${ }^{\mathrm{b}} \mathrm{CH}>\operatorname{SLM}(P=0.006), \mathrm{D}(P=0.010)$

Table 4 Tobacco, alcohol and other illicit drug use by methamphetamine use pattern during pregnancy

\begin{tabular}{|c|c|c|c|c|c|c|c|c|}
\hline & \multicolumn{8}{|c|}{ Methamphetamine use pattern during pregnancy } \\
\hline & \multicolumn{2}{|c|}{ Consistently high $(n=56)$} & \multicolumn{2}{|c|}{ Increasing $(n=18)$} & \multicolumn{2}{|c|}{ Stable low/moderate $(n=49)$} & \multicolumn{2}{|c|}{ Decreasing $(n=68)$} \\
\hline & $n$ & $\%$ & $n$ & $\%$ & $n$ & $\%$ & $n$ & $\%$ \\
\hline \multicolumn{9}{|l|}{ Tobacco } \\
\hline Use during pregnancy & 46 & 82.1 & 16 & 88.9 & 42 & 85.7 & 53 & 77.9 \\
\hline \multirow[t]{4}{*}{ Number of cigarettes/day } & Mean & SD & Mean & SD & Mean & SD & Mean & SD \\
\hline & 9.70 & 10.65 & 6.45 & 5.83 & 6.77 & 7.93 & 6.14 & 6.64 \\
\hline & Median & Range & Median & Range & Median & Range & Median & Range \\
\hline & 6 & $0-47$ & 5 & $0-20$ & 3 & $0-33$ & 4 & $0-23$ \\
\hline \multicolumn{9}{|l|}{ Alcohol } \\
\hline Use during pregnancy & $14^{\mathrm{a}}$ & 25.0 & 6 & 33.3 & 19 & 38.8 & $36^{\mathrm{a}}$ & 52.9 \\
\hline \multirow[t]{4}{*}{ Ounces of absolute alcohol/day } & Mean & SD & Mean & SD & Mean & SD & Mean & SD \\
\hline & 0.12 & 0.76 & 0.12 & 0.30 & 0.12 & 0.40 & 0.15 & 0.34 \\
\hline & Median & Range & Median & Range & Median & Range & Median & Range \\
\hline & 0.0 & $0-5.6$ & 0.0 & $0-1.2$ & 0.0 & $0-2.5$ & 0.0 & $0-1.6$ \\
\hline \multicolumn{9}{|l|}{ Marijuana } \\
\hline Use during pregnancy & 19 & 33.9 & 6 & 33.3 & 14 & 28.6 & 29 & 42.7 \\
\hline \multirow[t]{4}{*}{ Number of joints/day } & Mean & SD & Mean & SD & Mean & SD & Mean & SD \\
\hline & 0.07 & 0.19 & 0.06 & 0.15 & 0.09 & 0.29 & 0.12 & 0.28 \\
\hline & Median & Range & Median & Range & Median & Range & Median & Range \\
\hline & 0.0 & $0-1.02$ & 0.00 & $0-0.48$ & 0.0 & $0-1.67$ & 0.0 & $0-1.62$ \\
\hline Mean number of drugs used & 1.45 & $(\mathrm{SD}=0.91)$ & 1.61 & $(\mathrm{SD}=0.92)$ & 1.65 & $(\mathrm{SD}=0.97)$ & 1.94 & $(\mathrm{SD}=1.16)$ \\
\hline
\end{tabular}

${ }^{\mathrm{a}} \mathrm{CH}<\mathrm{D}(P=0.016)$

visits (Mean $=13$ visits) compared to women who were consistently high frequency users of MA (Mean $=8$ visits). We also observed that on average, women did not begin prenatal care for this pregnancy until the 2nd trimester and the women who decreased their MA use or who were stable low/moderate users sought prenatal care 
significantly earlier than the women who used MA at a consistently high level $(P=0.010)$. For reference, the comparison group (non-MA users) in IDEAL began prenatal care at 9 weeks gestation.

Polydrug Use by Patterns of Methamphetamine Use During Pregnancy

Table 4 compares the MA use pattern groups to use of other drugs of abuse during pregnancy. The prevalence of tobacco use was high among all groups (77.9-88.9\%), but did not differ by MA use pattern group. Similarly there were no group differences in cigarettes per day by MA pattern group. The prevalence of alcohol use was significantly higher in the decreasing group compared to the consistently high use group $(P=0.016)$. But the amount of absolute alcohol per day was not significantly different by MA pattern use group. In addition, there were no significant differences of MA pattern use group and prevalence or joints per day of marijuana. Lastly, there were no significant differences of MA pattern use group in the mean number of drugs used in this sample.

\section{Discussion}

This study recruited women from areas in the U.S. with relatively severe problems with MA and described patterns of MA use during pregnancy. On average, in this sample of 191 MA-using pregnant women, MA use declined from the first trimester of pregnancy through the last trimester. Importantly, $42.4 \%$ were still using in the third trimester $[15,21]$. While by no means definitive, the four use patterns developed in this study could serve as a starting point for future research investigating the relationship between quantity, frequency and persistence of MA use and possible long-term neonatal outcomes associated with prenatal MA exposure.

Looking more closely at individual patterns of MA use, it was observed that a little more than one-third of women decreased their use, while about $10 \%$ increased their use, and the remainder $(55.0 \%)$ did not change their use significantly over the course of their pregnancy. Shankaran et al. [21] observed a similar pattern for use of cocaine during pregnancy, with the two most frequent patterns of use characterized as consistently high and decreasing.

Sociodemographic characteristics did not differ significantly among the four MA use pattern groups. Future research should aim to identify factors other than age, race/ ethnicity and socioeconomic status that underlie differences in MA use patterns. It is quite possible that use patterns could be related to psychiatric comorbidity [30], partner conflict or abuse, availability of social support, and/ or utilization of treatment services. We did observe that women who decreased their use of MA over the course of pregnancy had a greater number of prenatal care visits, suggesting that prenatal care might have an impact on reducing MA use, or a less optimistic interpretation, is that women who decrease their MA use are simply more likely to visit prenatal care providers.

Contrary to our hypothesis, women who decreased their MA use were more likely to use alcohol than women who were consistently high users of MA throughout pregnancy. This finding is difficult to interpret, but we can speculate that one reason for it is that the women might think alcohol is less harmful than MA. While all women should be advised to eliminate or at least decrease their MA use during pregnancy, clinicians should remain vigilant regarding concomitant or increased alcohol use. Another explanation for the finding is that reducing MA use triggers withdrawal symptoms that could lead to self-medication with alcohol. If confirmed, this is a potentially serious and compensatory correlate of decreasing MA use during pregnancy, given the known adverse neonatal effects of alcohol. More intervention including retention in treatment may be needed to support decreasing or quitting MA.

The present study has many strengths and noteworthy methodological advantages. It is the first of its kind to explore patterns of MA use during pregnancy, it has a relatively large sample size, it uses structured interviews administered by trained research personnel, it uses a detailed questionnaire to obtain substance use history during each trimester for individual drugs, the levels of use for each drug. In addition, a study such as this opens the door for new investigations into how much MA is used by pregnant women and the patterns of their use.

Nevertheless, the study has some potential limitations. First, selection bias may be an issue because a substantial proportion of women declined to participate at an early stage in the study and therefore, the findings may not be generalizable to all MA-using pregnant women. It is possible that, on average, women who refused to participate would be more likely to have more severe MA problems. Another potential limitation of the study is that women may not have been able to recall the timing and amount of MA use during their pregnancy; however other research supports the use of the calendar method to overcome recall bias [23]. In addition, Jacobson and colleagues [23] demonstrate that the correlation between antenatal and retrospective reports of cocaine use during pregnancy was higher than any of the other drugs used during pregnancy.

More information is critically needed about the effects of not only maternal drug use, but also the effects of other adverse life circumstances that often occur in tandem with illicit drugs on long-term development of children, family functioning and quality of life. This study underscores the fact that clinicians who care for pregnant women should be 
comprehensively assessing patients for maternal drug use, and in areas affected by MA, allocation of resources should be planned for intervention with MA-using pregnant women.

Acknowledgments This study was supported by NIDA grant \# R01DA014948 and in part by the National Center for Research Resources, grant \# 3 M01 RR00425 and P20 RR11091.

Open Access This article is distributed under the terms of the Creative Commons Attribution Noncommercial License which permits any noncommercial use, distribution, and reproduction in any medium, provided the original author(s) and source are credited.

\section{References}

1. Lukas, S. E. (1997). National consensus meeting on the use, abuse, and sequelae of methamphetamine with implications for prevention, treatment, and research. Washington, DC: Center for Substance Abuse Treatment.

2. Maxwell, J. C., \& Rutkowski, B. A. (2008). The prevalence of methamphetamine and amphetamine abuse in North America: A review of the indicators, 1992-2007. Drug \& Alcohol Review, 27, 229-235.

3. Miller, M. A. (1997). Amphetamine misuse: International perspectives on current trends. In H. Klee (Ed.), History and epidemiology of amphetamine abuse in the United States (pp. 113134). Amsterdam: Harwood Academic Publishers.

4. Substance Abuse and Mental Health Services Administration. (2006). State estimates of past year methamphetamine use. In The NSDUH report. Rockville, MD.

5. Substance Abuse and Mental Health Services Administration. (2007). Methamphetamine use. In The NSDUH report. Rockville, MD.

6. Substance Abuse and Mental Health Services Administration. (2007). Results from the 2006 National Survey on Drug Use and Health: National findings. Rockville, MD: Office of Applied Studies.

7. Wilkins, C., Pledger, M., Bhatta, K., \& Casswell, S. (2001). Patterns of amphetamine use in New Zealand: Findings from the National Drug Survey. The New Zealand Medical Journal, 2004(117), U796.

8. Substance Abuse and Mental Health Services Administration. (2007). Treatment Episode Data Set (TEDS):1995-2005. In National admissions to substance abuse treatment services. Rockville, MD.

9. Substance Abuse and Mental Health Services Administration. (2008). Primary methamphetamine/amphetamine admissions to substance abuse treatment: 2005. In The DASIS report. Rockville, MD.

10. Substance Abuse and Mental Health Services Administration. (2008). Geographic differences in substance abuse treatment for methamphetamine/amphetamine and marijuana: 2005. In The DASIS report. Rockville, MD.

11. Substance Abuse and Mental Health Services Administration. (2006). Methamphetamine/amphetamine treatment admissions in urban and rural areas: 2004. In The DASIS report. Rockville, MD.

12. Derauf, C., Katz, A. R., Frank, D. A., Grandinetti, A., \& Easa, D. (2003). The prevalence of methamphetamine and other drug use during pregnancy in Hawaii. Journal of Drug Issues, 33, 1001-1016.

13. Smeriglio, V. L., \& Wilcox, H. C. (1999). Prenatal drug exposure and child outcome: Past, present, future. Clinics in Perinatology, 26, 1-16.
14. Arria, A. M., Derauf, C., La Gasse, L. L., Grant, P., Shah, R., Smith, L., et al. (2006). Methamphetamine and other substance use during pregnancy: Preliminary estimates from the Infant Development, Environment, and Lifestyle (IDEAL) Study. Maternal and Child Health Journal, 10, 293-302.

15. Smith, L. M., La Gasse, L. L., Derauf, C., Grant, P., Shah, R., Arria, A., et al. (2008). Prenatal methamphetamine use and neonatal neurobehavioral outcome. Neurotoxicology and Teratology, 30, 20-28.

16. Smith, L. M., La Gasse, L. L., Derauf, C., Grant, P., Shah, R., Arria, A., et al. (2006). The Infant Development, Environment, and Lifestyle Study: Effects of prenatal methamphetamine exposure, polydrug exposure, and poverty on intrauterine growth. Pediatrics, 118, 1149-1156.

17. Little, B. B., Snell, L. M., Gilstrap, L. D., III \& Johnston, W. L. (1990). Patterns of multiple substance abuse during pregnancy implications for mother and fetus. Southern Medical Journal, 83, 507.

18. Bauer, C. R., Shankaran, S., Bada, H. S., Lester, B., Wright, L. L., Krause-Steinrauf, H., et al. (2002). The Maternal Lifestyle Study: Drug exposure during pregnancy and short-term maternal outcomes. American Journal of Obstetrics and Gynecology, 186, 487-495.

19. Lester, B. M., La Gasse, L., Tronick, E. Z., Seifer, R., Bauer, C. R., Shankaran, S., et al. (2002). The Maternal Lifestyle Study: Effects of substance exposure during pregnancy on neurodevelopmental outcome in 1-month-old infants. Pediatrics, 110, 1182.

20. Hollingshead, A. B. (1975). Four factor index of social status. New Haven, CT: Department of Sociology, Yale University.

21. Shankaran, S., Das, A., Bauer, C. R., Bada, H., Lester, B., Wright, L. L., et al. (2004). Association between patterns of maternal substance use and infant birth weight, length, and head circumference. Pediatrics, 114(2), e226-234.

22. Singer, L., Arendt, R., Farkas, K., Minnes, S., Huang, J., \& Yamashita, T. (1997). Relationship of prenatal cocaine exposure and maternal postpartum psychological distress to child developmental outcome. Development and Psychopathology, 9, 473-489.

23. Jacobson, S. W., Chiodo, L. M., Sokol, R. J., \& Jacobson, J. L. (2002). Validity of maternal report of prenatal alcohol, cocaine and smoking in relation to neurobehavioral outcome. Pediatrics, 109, 815-825.

24. Richardson, G. A., \& Day, N. L. (1994). Detrimental effects of prenatal cocaine exposure: Illusion or reality? Journal of the American Academy of Child and Adolescent Psychiatry, 33, 28-34.

25. Richardson, G. A., Hamel, S. C., Goldschmidt, L., \& Day, N. L. (1999). Growth of infants prenatally exposed to cocaine/crack: Comparison of a prenatal care and a no prenatal care sample. Pediatrics, 104(2), e18.

26. Lester, B. M., \& Tronick, E. Z. (2004). History and description of the Neonatal Intensive Care Unit Network Neurobehavioral Scale. Pediatrics, 113, 634-640.

27. Jacobson, J. L., Jacobson, S. W., \& Sokol, R. J. (1994). Effects of prenatal exposure to alcohol, smoking, and illicit drugs on postpartum somatic growth. Alcoholism, Clinical and Experimental Research, 18, 317-323.

28. Jacobson, J. L., Jacobson, S. W., Sokol, R. J., Martier, S. S., Ager, J. W., \& Shankaran, S. (1994). Effects of alcohol use, smoking, and illicit drug use on fetal growth in black infants. The Journal of Pediatrics, 124, 757-764.

29. Jacobson, S. W., Jacobson, J. L., Sokol, R. J., Martier, S. S., \& Chiodo, L. M. (1996). New evidence for neurobehavioral effects of in utero cocaine exposure. The Journal of Pediatrics, 129, 581-590.

30. Semple, S. J., Zians, J., Strathdee, S. A., \& Patterson, T. L. (2007). Psychosocial and behavioral correlates of depressed mood among female methamphetamine users. Journal of Psychoactive Drugs, (Suppl 4), 353-366. 